\title{
INVESTIGATIONS ON THE EFFECT OF WALL THICKNESS ON MAGNETIC ADHESION FOR WALL CLIMBING ROBOTS
}

\author{
${ }^{* 1}$ Jaise Jose, ${ }^{1}$ D. Dinakaran, ${ }^{1}$ M.M. Ramya, ${ }^{1}$ RM. Kuppan Chetty, ${ }^{2}$ Mohammad O. Tokhi, ${ }^{2}$ Tariq P. \\ Sattar \\ ${ }^{1}$ Centre for Automation and Robotics, School of Mechanical Sciences, Hindustan Institute of \\ Technology and Science, Chennai - 603103 \\ ${ }^{2}$ School of Engineering, London South Bank University, United Kingdom.
}

\begin{abstract}
The focus of this work is to investigate the adhesion characteristics of a permanent magnet arrangement over ferromagnetic surfaces for wall climbing robot applications. The changes in wall thickness affect the adhesion characteristics of the robot, this in turn influences the payload and alters the operating conditions. The effect of varying the wall thickness on the adhesion strength of a wall-climbing robot is an area barely investigated and this is being explored in this work. A two-dimensional model of the adhesion mechanism and the ferromagnetic surface is developed and simulated in this study. The adhesion characteristics are studied for different thicknesses of the ferromagnetic surface with different grades of the magnet. Two different standoff distances which comprise the gap between the magnet and the surface to be inspected are investigated therein. Experimental studies are also carried out to measure the performance, and the results show a strong correlation with the simulation results. Simulation with experimental validation of magnetic adhesion presented will provide better insights into magnetic wall climbing systems.
\end{abstract}

\section{Key Words}

Wall climbing robot; Mobile robot; Permanent magnets; FEMM; Magnetic adhesion

\section{Introduction}

In the era of recent technical advancements, Wall-Climbing Robots (WCRs) have gained good traction of attention in the industry. The gained interest can be attributed to its profound uses in industrial applications such as inspection and maintenance. Wall climbing robots are capable of performing extremely difficult tasks in hazardous environments often involving high altitudes. The method of adhesion is one of the major design aspects that has to be considered in developing WCR for climbing vertical wall surfaces [1]. The adhesion principle used in vertical climbing is mainly subdivided into five categories [1-2], namely vacuum suction [3], biometric [4 - 7]], gripping [8 - 9], rail-guided [10-12] and magnetic [13] adhesion methods.

Vacuum suction provides the required adhesion force based on either suction cups or negative pressure thrust [3][25]. The adaptability to a variety of ferrous to non-ferrous surfaces such as glass, steel, tiles, and concrete makes this the commonly used adhesion method amongst the WCRs. When the wall surfaces are in complex environments, the gripping type [8] is found appropriate as an adhesion mechanism. The climbing robots which use gripping mechanisms are operated along with structures such as beams, pipes, columns, ducts, and environments where careful monitoring of the forces may be involved [9].

In biometric type adhesion mechanisms [4][23][24], Geckos are used to provide the necessary stickiness. These sticky type geckos adhere to surfaces using microscopic hair patches. The mechanism

*corresponding Author: jaisejose87@gmail.com 1 
works for dry adhesion through van der Waals forces. In rail-guided type adhesion [10][11] mechanism for climbing robots, the rails are laid out in advance where the wheel traction is used for climbing by the robot. The rail acts as a guiding mechanism for the robot to slide, and it also provides holding to the surface preventing the robot from falling off.

Among the above-mentioned adhesion mechanisms, the vacuum suction remains most popular due to its wide adaptability to surfaces and the adhesion force it generates but is limited to smooth surfaces [1]. Gripping type and rail-guided type mechanisms provide good payload capabilities but have very restricted operation region, which is their major drawback. Similarly, the payload capability is very low in the biometric type adhesion based on Geckos [1].

Many structures which are to be critically inspected in the industry are made out of ferrous material. Permanent magnet provides adhesion with zero power consumption, high payload capability and safe operation in case of power failure. Magnetic adhesion is accomplished in WCRs generally by using magnetic wheels, magnetic tracks, or the base of the body holds the magnets [13]. This paper considers a four-wheeled robot for inspection purposes based on skid steer mechanism with a payload in the range of $40-50 \mathrm{~kg}$.

A variety of investigations are offered on how adhesion varies with respect design parameters such as magnetic arrangements, flux concentration plate and air gap [22][13]. However, studies relating to adhesion performance with respect to varying surface thickness is subtle. The aim of the work reported in this paper is to investigate the adhesion performance of flux concentrator/yoke [12] on ferromagnetic surfaces with varying surface thickness both in simulations as well as through experimental tests.

The rest of the paper is structured as follows: Section 2 explains the materials used, software used and the experimental setup. Section 3 presents and discusses the simulation and experimental results of the work done. Finally, section 4 concludes the paper and discusses the future scope of the paper.

\section{Materials and methods}

The work carried out is to study the magnetic adhesion of an arrangement of neodymium magnets against walls of various thicknesses. The simulation studies are carried out using FEMM and the results are verified experimentally.

\subsection{Materials Used}

The materials used in the simulation, as well as the experiments, comprise of ferromagnetic surface, permanent magnets and flux concentrator/yoke.

\subsubsection{Ferromagnetic surface}

The surface material to be climbed is made up of low carbon steel which is widely used in storage tanks and other industrial applications. The plate thickness of such material varies from $1 \mathrm{~mm}$ to $15 \mathrm{~mm}$ and is used in this work. In the simulations, 1020 steel is used as the material and the properties specified in the built-in library are presented in Table 1. 
Table 1: Properties1020 steel

\begin{tabular}{|l|l|}
\hline Saturation flux density $\mathrm{B}_{\text {sat }}$ & $\mathrm{NaN}$ \\
\hline Coercivity $\mathrm{H}_{c}, \mathrm{~A} / \mathrm{m}$ & 0 \\
\hline Relative permeability $\mu$ & 760 \\
\hline Electric conductivity $\gamma,[\mathrm{MS} / \mathrm{m}]$ & 5.8 \\
\hline
\end{tabular}

\subsubsection{Permanent magnets}

$\mathrm{NdFeB}$ magnets or as they are commonly referred to as Neodymium magnets are counted among the most powerful permanent magnets in the world. These Magnets are made of an alloy which primarily consists of Neodymium, Iron and Boron and is chemically written as Nd2Fe14B. These magnets have a naming scheme that begins with $\mathrm{N}$ which is for Neodymium and is then followed by two numbers which give the maximum energy product in Mega-Gauss Oersteds (MGOe). The range of available ready for supply in the market magnets starts at N30 and goes up to N52 but the theoretical value goes to the maximum value of N64 (relating to the strength of magnetic field output and resistance to demagnetization).

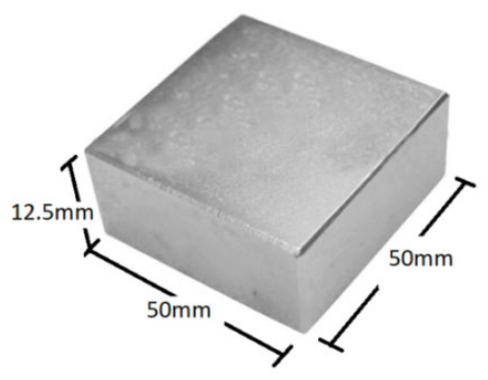

Figure 1: Dimensions of magnet used in the study

Figure 1 shows the physical dimensions of the N35 magnets used in the study and Table 2 [19] gives the properties of the magnets N35 and N52 used in the simulations. The adjacent magnets used in the arrangement is placed in opposite polarity, the magnets at the end are of similar polarity.

Table 2: Properties N35 and N52 magnets[19]

\begin{tabular}{|c|c|c|c|c|}
\hline $\begin{array}{c}\text { Grade } \\
\text { of } \\
\text { Magnets }\end{array}$ & $\begin{array}{c}\text { Energy product } \\
\text { of the magnet } \\
\mathrm{BH} \text { max, MGOe }\end{array}$ & $\begin{array}{c}\text { Remanent } \\
\text { magnetization }\end{array}$ & $\begin{array}{c}\text { Coercive } \\
\text { force }\end{array}$ & $\begin{array}{c}\text { Electric } \\
\text { Conductivity }\end{array}$ \\
\hline $\mathrm{N}, \mathrm{T}$ & $\mathrm{H}_{\mathrm{cB}}, \mathrm{KA} / \mathrm{m}$ & $\gamma, \mathrm{MS} / \mathrm{m}$ \\
\hline $\mathrm{N} 52$ & 34 & 1.2 & 905 & 0 \\
\hline
\end{tabular}




\subsubsection{Flux concentrator/ Yoke}

The magnets provide better adhesion when placed inside of a material with high permeability. The improvement in adhesion for such designs is reported in previous studies [16] [22] and this material is named yoke as shown in Figure 2 [21] [22] [14]. Low carbon steel block is pocket milled to hold the magnets as shown in Figure 2. Three neodymium grade N32 magnets with dimensions $50 \times 50 \times 12.5 \mathrm{~mm}$ were arranged as shown in Figure 4(b) in the test apparatus. The properties used for this are the same as that of 1020 steel specified in Table 2 .

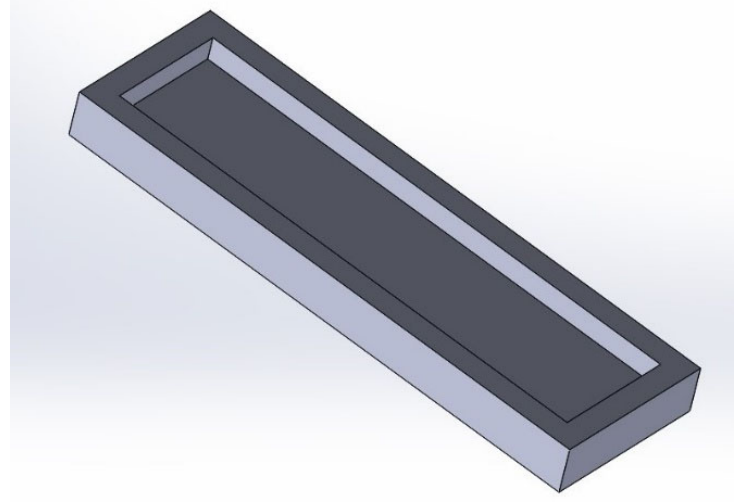

(a)

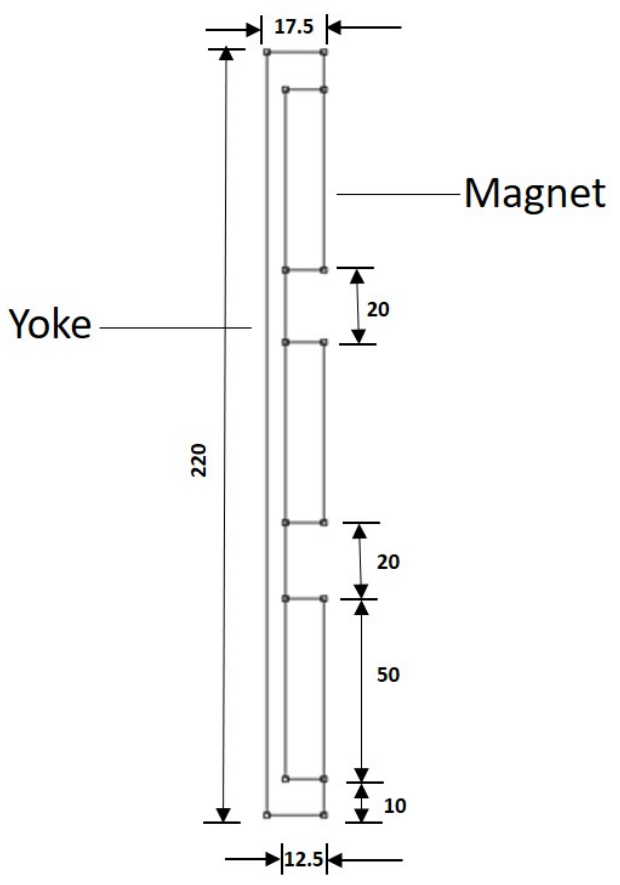

(b)

Figure.2 (a) CAD model of yoke (b) Dimensions of yoke and magnets (all measurements in $\mathrm{mm}$ ) arranged in simulation

\subsection{Simulation using Finite Element Method}

The finite element simulation is carried out using the FEMM v4.2 [15] [16], software for simulating magnetic and electromagnetic phenomena in a two-dimensional environment. The simulation considers the Yoke material and surface material to be made of steel and is surrounded by air. The simulation problem here is a magneto-statics problem [15]. Magnetostatics problems are structured in three stages: pre-processing, processing and post-processing [16].

The problem begins with specifying the type of problem as magnetostatics. The model is drawn using the pre-processor modes. Set the problem Type to be planar. Make sure that Length Units is set to millimetres and that the Frequency is set to 0 and the depth for the problem is set.

The drawing of the model is done using the pre-processor tools that are present in the FEMM 
toolset. The initial step involves defining the geometry of the problems at hand. Pre-processor tools consist of options to define nodes in the problem domain, line alongside with arc segments are used to join the nodes and thus build a model. The subsequent step after the model is built involves specifying the material and selecting the boundary.

The next step is the identification of the block materials properties. FEMM has a built-in library that allows a variety of materials. This simulation uses four materials namely, N35 magnets, yoke to hold the magnets made out of 1020 steel, surface under investigation made of 1020 steel, air as the material for the enclosure.

The boundary is set up for modelling a finite region of available space and the material is specified as air. Figure 3 shows the model and the material assignments made. In the next step, the continuous space is converted into discrete space elements for easy solving of problem space. This process is called meshing and is carried out by FEMM. The large problem is split into a large number of smaller triangles or triangular meshes and sizes of the meshes to reduce the complexity of the computation. After splitting up the problem domain, the finite element method is applied. The time required for the simulation depends on the nature of the problem. This problem deals with linear magneto-statics problems, which takes the least amount of time for solving.

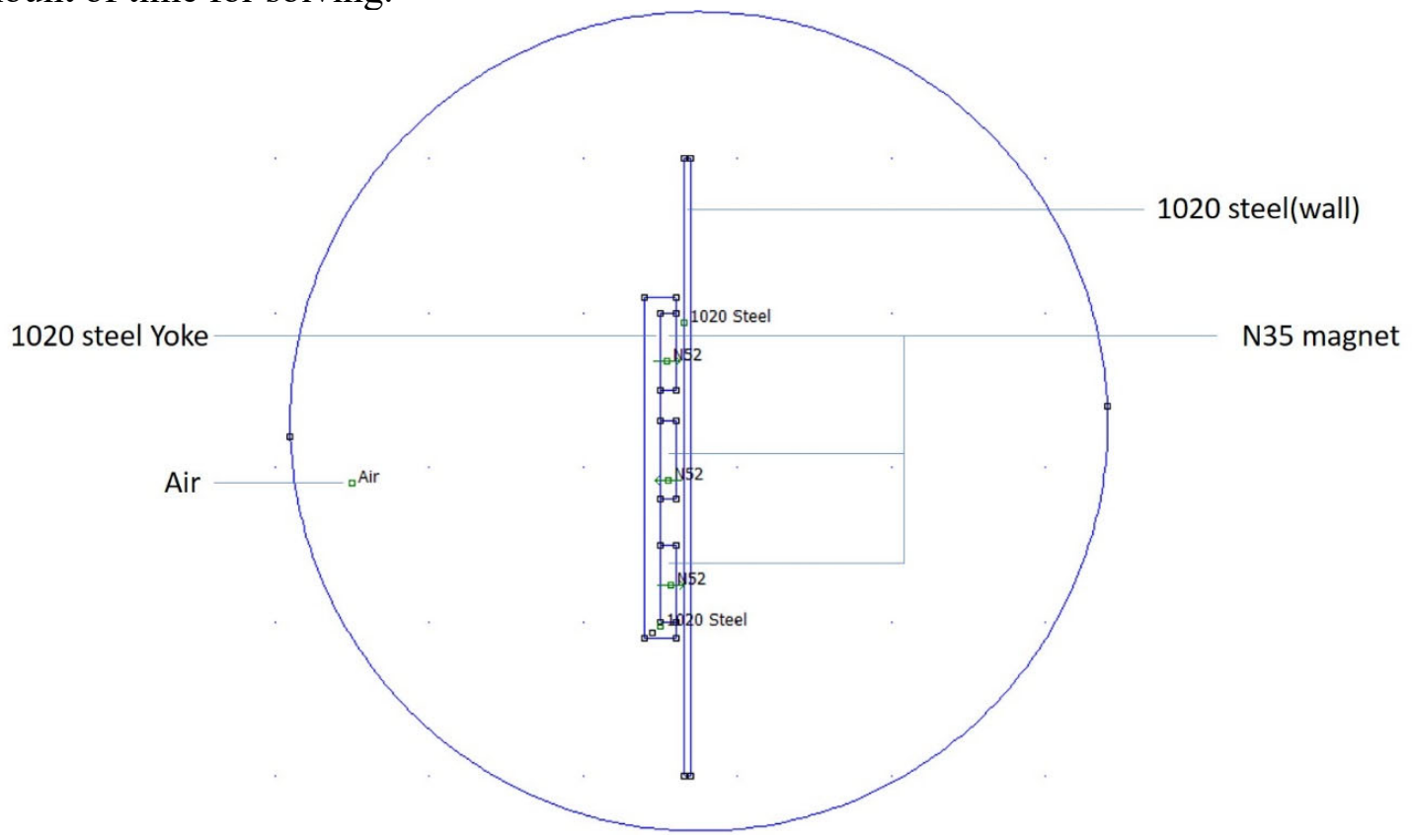

Figure 2. FEMM model for the magnet arrangement inside of a yoke against the wall plate

\subsection{Experimental setup}

To verify the results obtained in simulations a setup to measure the force generated by the arrangement of magnet was set up as shown in Figure.4.

Three neodymium magnets of grade N35 with dimensions of $50 \times 50 \times 12.5 \mathrm{~mm}$ were used in this experiment. The magnets were placed carefully inside the flux concentrator yoke with dimensions $230 \times 70$ $\mathrm{mm}$ and thickness of $22.5 \mathrm{~mm}$ and a slot of $12.5 \mathrm{~mm}$ depth and $210 \mathrm{~mm}$ wide to hold the magnets. The polarity of the magnets arranged as specified in the order so that the magnets, in the end, will have the same polarity whereas the middle one will have reverse polarity. The yoke arranged with magnets was 
attached to an aluminium plate with screws to adjust standoff distance. Subsequently, the yoke was placed attached to the surface plate to be tested.

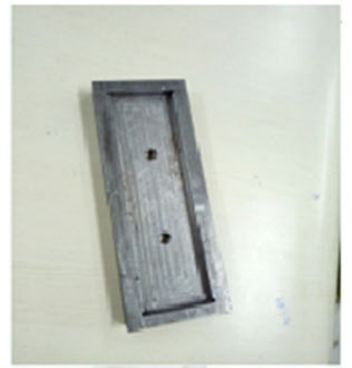

(a)

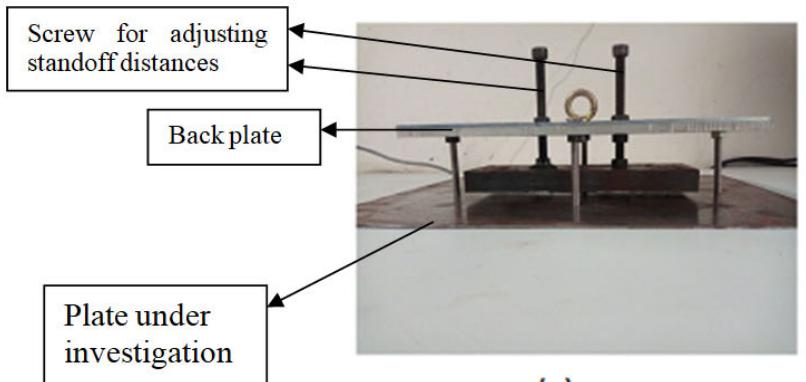

(c)

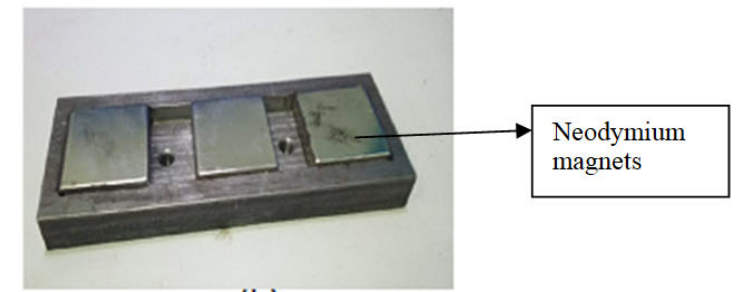

(b)

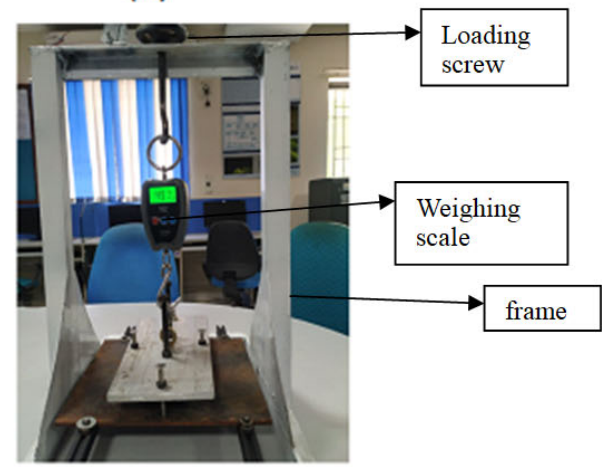

(d)

Figure.3: (a) Flux concentrator (b) Magnets arranged inside of a Flux concentrator /Yoke c) magnetic arrangement at a distance of $10 \mathrm{~mm} . \mathrm{d}$ ) Apparatus to measure the force produced by magnetic arrangement against the steel plate

This arrangement was subsequently placed inside of a specially designed frame and the plates were screwed where the pull-off load tests can be conducted by adjusting the load screw as shown in Figure 4 (d). As per the arrangement; load acting can be viewed on the weighing scale attached. Then the load screw is adjusted thus leading to an increase in load and the reading on scale increases. On a point, after it reaches maximum the adhesion starts to drop and this point has to be noted. This operation is repeated with ferrous plates of various thicknesses.

\section{Results and discussion}

\subsection{Simulation of magnetic adhesion force using FEMM}

Two simulation sets were carried out for two standoff distances using FEMM to study the adhesion characteristics. Two grades of magnets, N35 and N52 were used in the simulations as the N35 is widely available in the market and the N52 is the highest grade commercially available. These were used to obtain four sets of results, and these are shown in Table 3. The values are also plotted in Figure 5 for a better comparison of results. The investigation shows the effect of wall thickness in predicting the magnetic adhesion.

For the first set of simulation, a distance of $5 \mathrm{~mm}$ was set as the standoff distance between the magnet and the surface under investigation. The N35 magnet varied from $174.578 \mathrm{~N}$ to $1297.5 \mathrm{~N}$ for thicknesses of $1 \mathrm{~mm}$ to $15 \mathrm{~mm}$ in simulations and when standoff distance was increased to $10 \mathrm{~mm}$ the force range 
reduced from $129.044 \mathrm{~N}$ to $666.009 \mathrm{~N}$. A similar trend was noted in N52 magnets with the force increasing from $211.367 \mathrm{~N}$ to $1762.07 \mathrm{~N}$ for $5 \mathrm{~mm}$ standoff distance and $156.664 \mathrm{~N}$ to $937.352 \mathrm{~N}$ for $10 \mathrm{~mm}$ standoff distance.

Table 3: FEMM simulation results for magnetic adhesion for the arrangement of N35 and N52 magnets at standoff distances (SOD) of $5 \mathrm{~mm}$ and $10 \mathrm{~mm}$ for the different wall thickness.

\begin{tabular}{|c|c|c|c|c|}
\hline \multirow{2}{*}{$\begin{array}{c}\text { VARYING } \\
\text { PLATE } \\
\text { THICKNESS } \\
(\mathrm{mm})\end{array}$} & \multicolumn{3}{|c|}{$|\mathrm{F}|$ experienced in newtons(N) } & \multicolumn{2}{c|}{$\mid \begin{array}{c}|c| \\
\text { SOD } 5 \mathrm{~mm} \text { experienced in newtons(N) } \\
\text { SOD 10 mm }\end{array}$} \\
\cline { 2 - 5 } & GRADE N35 & GRADE N52 & GRADE N35 & GRADE N52 \\
\hline 1 & 174.587 & 211.367 & 129.044 & 156.664 \\
\hline 2 & 365.579 & 442.312 & 262.047 & 320.256 \\
\hline 3 & 557.463 & 673.703 & 377.038 & 470.095 \\
\hline 4 & 750.926 & 911.583 & 461.076 & 598.632 \\
\hline 5 & 911.949 & 1141.48 & 524.949 & 689.813 \\
\hline 6 & 1019.03 & 1326.19 & 580.486 & 765.716 \\
\hline 7 & 1103.37 & 1453.37 & 620.635 & 831.59 \\
\hline 8 & 1174.79 & 1552.76 & 644.538 & 879.299 \\
\hline 9 & 1225.37 & 1629.73 & 656.616 & 908.263 \\
\hline 10 & 1259.56 & 1677.87 & 661.685 & 922.817 \\
\hline 11 & 1277.73 & 1722.1 & 665.55 & 931.756 \\
\hline 12 & 1286.21 & 1740.49 & 665.66 & 934.095 \\
\hline 13 & 1292.94 & 1752.93 & 666.813 & 937.813 \\
\hline 14 & 1296.84 & 1759.86 & 666.371 & 937.766 \\
\hline 15 & 1297.5 & 1762.07 & 666.009 & 937.352 \\
\hline
\end{tabular}

It can be seen in the simulation results that adhesion varied sharply until the thickness reached 10 $\mathrm{mm}$. There was no further appreciation in adhesion for magnets N35 and N52 at both standoff distances. 


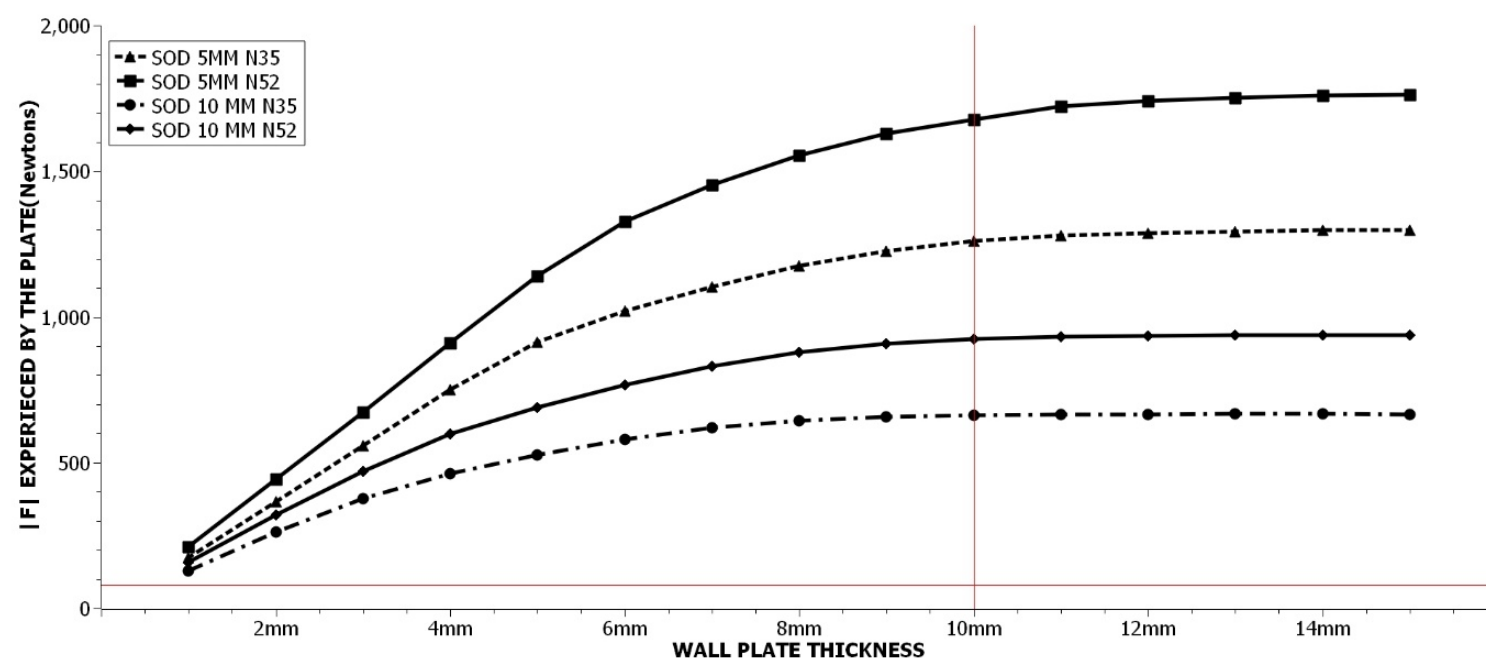

Figure. 5: Graphical representation of Table 3 data. (SOD: standoff distance)

\subsection{Experimental studies}

Four sets of data were obtained from the simulation results for two standoff distances for N35 and N52 magnets. As noted from the graphical representations, all the four sets followed a similar trend for the plates. This was verified for magnet arranged inside of yoke at a distance of $10 \mathrm{~mm}$ against test plates. This was followed by assessing the force generated against the plate of $10 \mathrm{~mm}$ to check the trend of simulation. This experiment was repeated for six different plate thicknesses and the results were compared with simulation results, and this is shown in Table 4.

Table 4: Simulation vs. experimental results

\begin{tabular}{|c|c|c|c|}
\hline $\begin{array}{c}\text { Plate } \\
\text { thickness(mm) }\end{array}$ & $\begin{array}{c}\text { Simulated results } \\
\text { (Kilograms) }\end{array}$ & $\begin{array}{c}\text { Experimental } \\
\text { results } \\
\text { (Kilograms) }\end{array}$ & Error \% \\
\hline 1 & 15 & 14 & 7.14 \\
\hline 2 & 27 & 28 & 3.57 \\
\hline 5 & 52 & 52 & 0 \\
\hline 6 & 55 & 58 & 5.17 \\
\hline 8 & 62 & 59 & 5.08 \\
\hline 10 & 72 & 66 & 9.09 \\
\hline
\end{tabular}




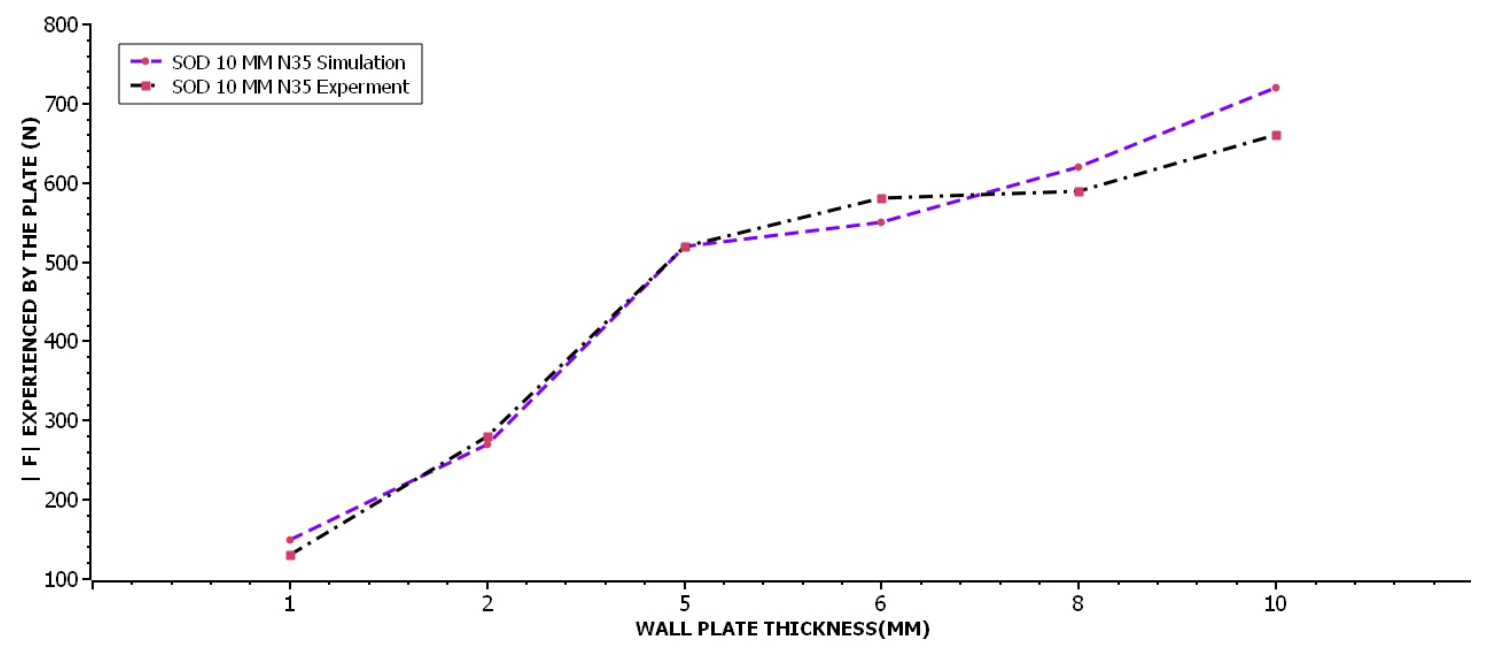

Figure. 6: Comparison of experimental data vs. the simulations

Figure 6 shows graphical representation of the results in Table 4. Both the results are found to be in near agreement with errors of less than $\pm 10 \%$.

\section{Conclusion}

In this study, the effect of ferromagnetic wall thickness on magnetic adhesion of Neodymium magnet arrangement has been studied using simulations and the results have been verified experimentally. Magneto-statics simulation has been carried out using FEMM software for Neodymium magnets arrangement against ferrous surface climbed. Both magnetic arrangements of N35 and N52 at standoff distances of $5 \mathrm{~mm}, 10 \mathrm{~mm}$ showed a comparable fashion of adhesion. Also, this trend saturates around 10 $\mathrm{mm}$ of wall thickness and any further increase in thickness would not contribute much to adhesion. The simulation results have been practically verified with N35 at a standoff distance of $10 \mathrm{~mm}$ and the results have shown a strong correlation with the simulation results.

The ferromagnetic structures constructed may include materials of different types and of varying thicknesses. From the simulation and experimental results, it is clear that increasing wall plate thickness significantly increases the magnetic adhesion. In the event of the robot manoeuvring from a thick plate to thin sheet, there will be a considerable drop in magnetic adhesion and thus this study is a significant insight in robot design. The work done in this paper was limited to one specific material and this could further be extended with different material properties. Also, adaptive control systems which adapt to the changes in adhesion with surface thickness need to be investigated.

\section{Acknowledgement}

Authors would like to thank the Royal Academy of Engineering, UK for supporting this research work under Industry-Academia Partnership Programme, Newton funding, the project numbered - IAPP18-19\27

\section{References}

[1] Chu, B., Jung, K., Han, C.S. and Hong, D., 2010. A survey of climbing robots: Locomotion and adhesion. International journal of precision engineering and manufacturing, 11(4), pp.633-647. 
[2] Nansai, S. and Mohan, R., 2016. A survey of wall climbing robots: recent advances and challenges. Robotics, 5(3), p.14

[3] Brusell, A., Andrikopoulos, G. and Nikolakopoulos, G., 2016, June. A survey on pneumatic wallclimbing robots for inspection. In 2016 24th Mediterranean Conference on Control and Automation (MED) (pp. 220-225). IEEE.

[4] Hou, X., Su, Y., Jiang, S., Cao, P., Xue, P., Tang, T., Li, L. and Chen, T., 2019. Space climbing robot feet with microarray structure based on discrete element method. International Journal of Robotics and Automation, 34(1).

[5] Chattopadhyay, P. and Ghoshal, S.K., 2018. Adhesion technologies of bio-inspired climbing robots: A survey. International Journal of Robotics and Automation, 33(6)

[6] Menon, C. and Sitti, M., 2005, April. Biologically inspired adhesion based surface climbing robots. In Proceedings of the 2005 IEEE International Conference on Robotics and Automation (pp. 2715-2720). IEEE.

[7] Carlo, M. and Metin, S., 2006. A biomimetic climbing robot based on the gecko. Journal of Bionic Engineering, 3(3), pp.115-125

[8] Balaguer, C., Gimenez, A. and Abderrahim, C.M., 2002. ROMA robots for inspection of steel based infrastructures. Industrial Robot: An International Journal, 29(3), pp.246-251

[9] Krosuri, S.P. and Minor, M.A., 2003, September. A multifunctional hybrid hip joint for improved adaptability in miniature climbing robots. In 2003 IEEE International Conference on Robotics and Automation (Cat. No. 03CH37422) (Vol. 1, pp. 312-317). IEEE.

[10] Warszawski, A., 2003. Industrialized and automated building systems: A managerial approach. Routledge.

[11] Bach, F.W., Rachkov, M., Seevers, J. and Hahn, M., 1995. High tractive power wall-climbing robot. Automation in construction, 4(3), pp.213-224.

[12] Elkmann, N., Felsch, T., Sack, M., Saenz, J. and Hortig, J., 2002, October. Innovative service robot systems for facade cleaning of difficult-to-access areas. In IEEE/RSJ International Conference on Intelligent Robots and Systems (Vol. 1, pp. 756-762). IEEE.

[13] Jose,J.;Dinakaran,D.;Ramya,M.M.;Harris,D.G.A Survey on Magnetic Wall-Climbing Robots for Inspection. International Journal of Mechanical and Production Engineering Research and Development. Vol. 8, Issue 6, Dec 2018, 59-68

[14] Sahbel, A., Abbas, A. and Sattar, T., 2019. Experimental and Numerical Optimization of Magnetic Adhesion Force for Wall Climbing Robot Applications. International Journal of Mechanical Engineering and Robotics Research, 8(1), pp.18-24.

[15] Meeker, D., 2010. Finite element method magnetics. FEMM, 4, p.32.

[16] Baltzis, K.B., 2008. The FEMM Package: A Simple, Fast, and Accurate Open Source Electromagnetic Tool in Science and Engineering. Journal of Engineering Science \& Technology Review, 1(1)

[17] Meeker, D., 2005. Finite Element Method Magnetics. Version 4.2. User's Manual, September 26, 2006.

[18] https://www.first4magnets.com/tech-centre-i61/information-and-articles-i70/neodymium-magnetinformation-i82/common-applications-of-neodymium-magnets-i88 
[19] http://www.femm.info/wiki/NeoProperties,

[20] Howlader, M.O.F. and Sattar, T.P., 2016. Design and Optimization of Permanent Magnet Based Adhesion Module for Robots Climbing on Reinforced Concrete Surfaces. In Intelligent systems and applications (pp. 153-171).

[21] Hussain, S., Sattar, T.P. and Salinas, E., 2012. Parameter analysis and design framework for magnetic adhesion wall climbing wheeled robot. International Journal of Intelligent Systems Technologies and Applications, 11(1-2), pp.102-116.

[22] Sattar, T, Salman, H and Salinas, E (2011). Towards Optimum Design Of Magnetic Adhesion Wall Climbing Wheeled Robots. Khan, KM and Win, NL (ed.) 26th International Conference on CAD/CAM, Robotics and Factories of the Future 2011. Kuala Lumpur, Malaysia 26 - 28 Jul 2011 pp. 716-728

[23] Yu, Z., Shi, Y., Xie, J., Yang, S.X., Dai, Z., Design and analysis of a bionic adhesive foot for gecko robot climbing the ceiling (2018), International Journal of Robotics and Automation, 33 (4), pp. 445454

[24] Yu, Z., Yang, B., Yang, S.X., Dai, Z., Vertical climbing locomotion of a new gecko robot using dry adhesive material(2017), International Journal of Robotics and Automation, 32 (4), pp. 425-431.

[25] Fanni, M.A., Alkalla, M.G., Mohamed, A., Propeller-type skid steering climbing robot based on a hybrid actuation system (2018), International Journal of Robotics and Automation, 33 (3), pp. 258265. 